\title{
Scale-free dynamics in human neonatal cortex following perinatal hypoxia
}

James A Roberts ${ }^{1 *}$, Kartik K lyer ${ }^{1,2}$, Simon Finnigan², Sampsa Vanhatalo ${ }^{2,3}$, Michael Breakspear ${ }^{1}$

From Twenty Second Annual Computational Neuroscience Meeting: CNS*2013

Paris, France. 13-18 July 2013

Complications at birth can interrupt blood supply to the baby, leading to hypoxia in the neonatal cortex. Once oxygen supply resumes, cortical activity follows a stereotypical recovery sequence that includes a period termed burst suppression, during which the EEG exhibits sudden, irregular fluctuations of highly variable size and shape. Clinical outcome depends critically on this phase, ranging from complete recovery to permanent cognitive or motor disability and even death. Despite its importance in the recovery process, burst suppression's mechanisms remain poorly understood, and objective diagnostics are needed to guide treatment [1].

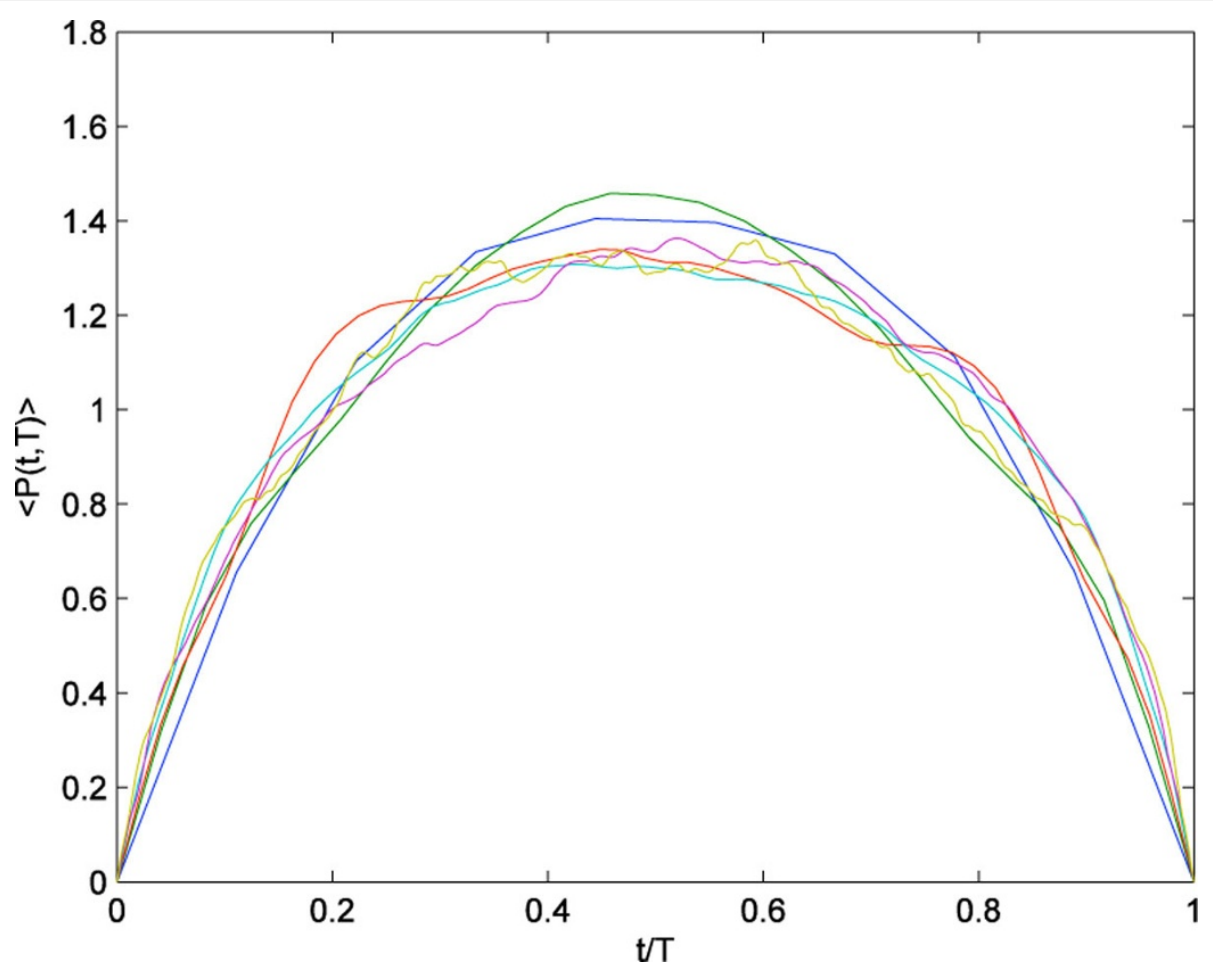

Figure 1 Example of single-subject average burst shapes collapsing to a simple symmetric functional form over temporal scales of $\mathrm{T}=40 \mathrm{~ms}-4 \mathrm{~s}$.

\footnotetext{
* Correspondence: james.roberts@qimr.edu.au

'Systems Neuroscience Group, Queensland Institute of Medical Research,

Herston, Brisbane, QLD 4006, Australia

Full list of author information is available at the end of the article
}

(c) 2013 Roberts et al; licensee BioMed Central Ltd. This is an Open Access article distributed under the terms of the Creative Commons 
Here, we analyze the statistical properties of burst suppression in neonatal EEG recordings and show that simple dynamical models capture key features of the data. We find that fluctuations in burst size exhibit long-tailed power law distributions spanning up to five orders of magnitude. Despite this immense variability, their average shape at all temporal scales can be rescaled to a near universal template (Figure 1). Deviations from universality include a flattening of fluctuation shapes at long time scales and the expression of leftward or rightward asymmetry. These features are consistent with the phenomenon of crackling noise that arises in disparate physical systems such as crumpling paper, magnetizing a ferromagnet, and earthquakes, all of which exhibit scale-free bursty events [2]. Similar behavior has recently been observed in neuronal avalanches recorded in cortical slices [3]. In our data, as in studies of crackling noise, the average shapes shed light on the underlying mechanisms [4]. Using simple phenomenological models, we show how changes to the average shapes can arise from different forms of state-dependent damping, representing resource depletion in cortical neurons. Statistical analysis of the variability and average shapes of bursts holds promise for new diagnostic opportunities in this critical clinical window and will inform future biologically-detailed models.

\section{Author details}

${ }^{1}$ Systems Neuroscience Group, Queensland Institute of Medical Research, Herston, Brisbane, QLD 4006, Australia. ${ }^{2}$ Centre for Clinical Research and Perinatal Research Centre, University of Queensland, Brisbane, QLD 4006,

Australia. ${ }^{3}$ Department of Children's Clinical Neurophysiology, Helsinki

University Central Hospital and University of Helsinki, Helsinki, Finland.

Published: 8 July 2013

\section{References}

1. Douglass LM, Wu JY, Rosman NP, Stafstrom CE: Burst suppression electroencephalogram pattern in the newborn: predicting the outcome. J Child Neurol 2002, 17(6):403-408.

2. Sethna JP, Dahmen KA, Myers CR: Crackling noise. Nature 2001, 410(6825):242-250

3. Friedman $\mathrm{N}$, Ito $\mathrm{S}$, Brinkman BA, Shimono M, DeVille RE, Dahmen KA, Beggs JM, Butler TC: Universal critical dynamics in high resolution neuronal avalanche data. Phys Rev Lett 2012, 108(20):208102.

4. Zapperi S, Castellano C, Colaiori F, Durin G: Signature of effective mass in crackling-noise asymmetry. Nature Phys 2005, 1(1):46-49.

doi:10.1186/1471-2202-14-S1-P36

Cite this article as: Roberts et al:: Scale-free dynamics in human neonatal cortex following perinatal hypoxia. BMC Neuroscience 2013 14(Suppl 1):P36.

\section{Submit your next manuscript to BioMed Central} and take full advantage of:

- Convenient online submission

- Thorough peer review

- No space constraints or color figure charges

- Immediate publication on acceptance

- Inclusion in PubMed, CAS, Scopus and Google Scholar

- Research which is freely available for redistribution

Submit your manuscript at www.biomedcentral.com/submit
C Biomed Central 